\title{
Which sport sponsorships most impact sponsor CSR image?
}

\author{
Abstract \\ Purpose This research seeks to investigate how organizations can utilize sport sponsorship to \\ build their corporate social responsibility (CSR) image effectively, by examining the \\ attributes of a sport property that are most conducive to a sponsor gaining CSR image \\ benefits.
}

Design/methodology/approach A between-subjects experimental design was employed, which simulated different sponsorship scenarios by varying community proximity (operationalized by property scope) and property engagement in community initiatives. Hypotheses were tested with a non-parametric bootstrapping-based procedure, using a panel sample of 400 .

Findings The results show that a sporting property's proactive community engagement is conducive to an enhanced CSR image for its sponsor, especially when the property operates on the national rather than grassroots level. Further analysis also demonstrates the critical contribution of altruistic motive attributions in the process.

Originality/value This study advances knowledge on how organizations may build their CSR image while leveraging on the strong audience involvement and the mass appeal of sport sponsorship. It is the first to offer insights into the extent to which a sports property's proactive engagement in the community, rather than that of the sponsoring firm itself, enhances CSR image for the sponsor, particularly if the property's community proximity is low. Furthermore, our results provide an in-depth understanding of the mechanisms determining the benefits that sponsors can reap from a property's activities. 


\section{Introduction}

Corporate social responsibility (CSR hereafter) is imperative to organizations worldwide (Vaaland, Heide and Grønhaug, 2008). This is not surprising as organizations compete for increasingly socially conscious shoppers, who now account for more than $90 \%$ of shoppers internationally (Brooks, 2013). Indeed, extant research has shown that CSR initiatives such as cause-related marketing, philanthropy and cause sponsorship (e.g., Simmons and BeckerOlsen, 2006) are capable of strengthening a firm's socially responsible image (e.g., Peloza and Shang, 2011), which in turn has been shown to benefit the firm on multiple fronts. For instance, CSR image is known to shape consumers' responses by fostering donations to a charity (e.g., Lichtenstein et al., 2004), building consumer identification with the company (e.g., Pérez, Salmones and del Bosque, 2013), and by improving evaluations of the firm's product (e.g., Brown and Dacin, 1997) or attitudes toward them (e.g., Berens et al., 2005). Financial benefits have been evidenced as well, with CSR increasing the firm's market value (e.g., Luo and Bhattacharya, 2006) and decreasing its stock price volatility (e.g., Luo and Bhattacharya, 2009).

These studies bring a collective answer to the question whether CSR activities can be advantageous for firms; however, studies addressing the question which CSR activities are most beneficial for firms are few and far between. Researchers have increasingly recognized that CSR initiatives are not created equal (Du et al., 2010), leading to an examination of the relative merits of cause promotion and advocacy advertising (i.e., Menon and Kahn, 2003), corporate and non-corporate source effects (i.e., Skard and Thorbjornsen, 2014), and the different attributes of a cause such as type, scope, and acuteness (i.e., Vanhamme et al., 2012). The current research introduces sport sponsorship to this stream of enquiries, seeking to determine its potential contribution to the firm's image as a socially responsible organization. Specifically, it examines the role of two attributes of a sponsored sport property 
that shape the effects of sponsorship on the sponsor's CSR image, namely community engagement and community proximity. It is important to note that this study focuses solely on image effects, not on any social impact that may be derived from the sponsorship.

Sponsorship holds great potential to build CSR image given its reputation as a powerful means for "publicizing and highlighting a transparent, consistent and socially responsible corporate image" (Jahadi and Acikdilli, 2009, p. 111). Yet, much of the literature has focused on the sponsorship of causes, with sport sponsorship typically conceived as less conducive to goodwill perceptions for the sponsors than the sponsorship of cultural or charitable properties (Meenaghan, 2001; Olson, 2010). This may stem from consumers assigning to sponsors stronger self-serving motives when supporting sports properties due to a lack of sincerity regarding their interest for the property (Speed and Thompson, 2000) and the suspicion that these properties' mass appeal is the real reason behind the sponsorship (Pappu and Cornwell, 2014). Hence, it is believed that heavy investment in these properties would be less likely to build an image as a socially responsible organization.

This state of affair notwithstanding, managers still devote the bulk of their sponsorship dollars to sports properties, which capture about $70 \%$ of sponsorship investments in North America (IEG, 2015). This can be explained by the benefits sport offers over other types of properties, such as the development of strong emotional bonds with the audience (e.g., Babiak and Wolfe, 2009), the opportunity for sponsors to engage the audience with their brand through event marketing (e.g., Close et al., 2010), as well as wider media coverage and thus indirect audience reach (e.g., Gijsenberg, 2014). For sponsors, such visibility implies a greater likelihood of stakeholder awareness by means of media presence and publicity (Varadarajan and Menon, 1988), which is lacking with other CSR activities (Du et al., 2010). Furthermore, sport commands a strong affective engagement by audiences (Walker and Kent, 2009); passion that can attract attention for causes and organizations associated with the sport 
(Babiak and Wolfe, 2009). Therefore, the decision to sponsor sport events to improve CSR image is both common and intentional (Plewa and Quester, 2011). One survey from IEG (2014) indicates that $26 \%$ of marketing managers declare that the ability to improve CSR image is extremely important in their decision-making in sponsorship. To improve CSR image, managers can either sponsor local sports association or sports clubs, which is perceived as a real contribution to sports development in the community by consumers (Sportbusiness, 2009), or sponsor a national property with substantial CSR initiatives (Lacey et al., 2010; Sheth and Babiak, 2010).

Nonetheless, no research has compared the effectiveness of these two strategies to achieve CSR image enhancement by means of sport sponsorship. Furthermore, limited academic research has examined how organizations may build their CSR image while leveraging on the strong audience involvement and the mass appeal of sport sponsorship (for an exception see Lacey et al., 2010). To that effect, this study investigates whether CSR image benefits can be accrued indirectly through sponsorship when it is the supported property that is actively engaged in the community. Close et al. (2006) showed that a sponsor that is more community oriented garners more favorable responses from consumers. As a result, community engagement has become a central tenet of many studies concerning CSR in sport (Lacey et al., 2010). Moreover, connecting to the local community through philanthropy or community programs has been identified as the key priority of professional sport organizations engaging in CSR (Sheth and Babiak, 2010). However, whether and how sport organizations' proactive community engagement benefits their sponsors remains unknown.

Furthermore, this study provides novel insights into the relevance of the property's community proximity, defined here as the perceived closeness of the property to its local community, by comparing CSR image benefits for sponsors of national versus grassroots sports properties. Much of the sponsorship literature dealing with CSR focuses on national 
entities (e.g., Lacey et al., 2010; Sheth and Babiak, 2010), understood in this paper as professional sport teams involved in a national league. Few authors have investigated grassroots properties (Quester et al., 2013), defined here as amateur teams playing in a local/regional league. Yet these properties have a unique position as they are by their very nature not only close to, but an integral facet of, their local community (Wicker et al., 2012).

From a theoretical standpoint, our results provide an in-depth understanding of the mechanisms determining the benefits that sponsors can reap from a property's activities. By evidencing how consumers' inferences of sponsor motives for supporting the property drive the effects on CSR image, we contribute to the literature in several ways. First, although the attribution of motives to sponsors is posited to drive consumer's response to CSR initiatives (i.e., Pappu and Cornwell, 2014); there is no evidence available in support of this key assumption. Furthermore, in going beyond previous findings showing the inference of altruistic motives to sponsors engaged directly in charitable behaviors (e.g., Rifon et al., 2004), our results show that such inferences occur even when the charitable behavior is performed by the sponsored property rather than by the firm itself. This research also offers managerial contribution since it indicates how to benefit from CSR image enhancement when supporting a mass appeal property such as a professional sporting club.

The remainder of the paper begins with the development of the theoretical framework founded on attribution theory and drawing on the sponsorship, cause-related marketing (CRM) and CSR literatures. The experimental design, sample and data collection are described next, prior to a description and discussion of results relating to hypotheses. The paper concludes by outlining theoretical and managerial implications, limitations, as well as future research directions. 


\section{Sport Sponsorship and Corporate Social Responsibility}

CSR, defined here as "a commitment to improve community well-being through discretionary business practices and contributions of corporate resources" (Kotler and Lee, 2004, p. 3), remains central to current business thinking and academic enquiry (Hildebrand, Sen and Bhattacharya, 2011). Importantly, the marketing literature emphasizes that a firm's CSR image, rather than its actual CSR performance, is critical to organizations (Bigné, Currás-Pérez and Aldás-Manzano, 2012) and should be the focus in understanding the consequence of CSR on economic performance. Hence, the beneficial impact of a strong CSR image on a wide array of consumer outcomes such as reputation, consumer attitudes, identification, and behavioral intentions (i.e., Berens et al., 2005; Lacey et al., 2010; Lichtenstein et al., 2004; Walker and Kent, 2009) and firm level outcomes such as financial performance (Luo and Bhattacharya, 2006) are well established in the literature. On the other hand, the investigations of different levers actionable by managers for improving CSR image are rare and authors are calling for more research investigating the antecedents of CSR image (e.g., Du et al., 2010; Vanhamme et al., 2012).

Importantly, causes that are highly visible in the public eye imply a greater likelihood of stakeholder awareness by means of media presence and publicity (Varadarajan and Menon, 1988). Such high visibility is an integral and unique characteristic of sport, which not only receives significant media attention and features prominently in many peoples' lives, but also commands a strong affective engagement of audiences and participants (Close et al., 2006; Walker and Kent, 2009) and is met with passion by many (Babiak and Wolfe, 2009). Sport is integral to society, economy and culture internationally but also relevant on national, regional and local levels (Jarvie, 2013).

Yet, the sponsorship of sport has received little academic attention in the CSR domain (Peloza and Shang, 2011). While some initial research has suggested the ability of sport 
sponsorship to build sponsor CSR image (i.e., Quester et al., 2013), empirical investigations of whether sport sponsorship can facilitate the development of CSR image are lacking. As a result, no guidance exists regarding the type of sport property that is most conducive to a socially responsible image for the sponsor. To that aim, the conceptual framework below illustrates the two main attributes of a sport property that determine the effectiveness of sponsorship from a CSR image standpoint: community engagement and community proximity.

\section{Conceptual framework}

The model in Figure 1 depicts the different factors leading to CSR image. First, a sporting property's proactive community engagement $(\mathrm{H} 1)$ and its community proximity (measured by the scope of the property as national versus grassroots) (H2), are both posited to foster the attribution of altruistic motives to the sponsor. Second, altruistic attributions are expected to mediate the effect of community engagement on CSR image (H3). Furthermore, our model posits that the impact of proactive community engagement on CSR image depends on the property's community proximity $(\mathrm{H} 4)$.

[Insert Figure 1 about here]

\section{Proactive community engagement of the sport property}

Community engagement is frequently discussed in studies examining CSR within the sport context (Lacey et al., 2010; Sheth and Babiak, 2010), with CSR "grounded in giving back to one's community" (Bradish and Cronin, 2009, p. 696). Hence, sporting bodies have increasingly embraced community engagement as an integral feature of their brands (Babiak and Wolfe, 2009). Such engagement aims to build goodwill for the property within stakeholder groups, including fans and the broader society, and may entail the establishment 
of charitable foundations, or the involvement in community development, youth or other outreach initiatives (Walker and Kent, 2009).

More recently, exploratory evidence showed that community engagement efforts can assist in sponsor recruitment and lead to increased sponsorship revenue (Babiak and Wolfe, 2009). As noted previously, a drawback of sport sponsorship is the inference of commercial intent which can impede the development of sponsors' CSR image (Meenaghan, 2001; Speed and Thompson, 2000). However, we argue here that if a sport property is strongly involved in goodwill-inducing behaviors such as proactively supporting its community, consumers are more likely to attribute altruistic motives to sponsors of that property. This prediction draws on extant literature, which has shown that a more favorable perception of a sport property fosters the development of altruistic motive attributions towards its sponsor (Dean, 2002). Sport organizations can develop such favorable perceptions by means of CSR activities, such as community involvement (Walker and Kent, 2009). Indeed, Mazodier and Rezaee (2013) show that, although shareholders react negatively to new sponsorship announcements, this effect is less pronounced for philanthropic than for commercial sponsorships. Hence, our first hypothesis proposes that altruistic attributions of motives to the sponsor are stronger if the sport property is established as a strong contributor to the community:

H1: A sports property's community engagement is positively associated with attribution of altruistic motives to its sponsor.

\section{Community proximity}

While sport properties can proactively develop their image as socially responsible citizens, it can also be argued that certain types of properties are perceived as engaged in their community merely due to proximity. Specifically, grassroots properties are, by their very nature, close to the community in which they operate, previously described as the "backbone 
of the voluntary sport system" (Wicker et al., 2012, p. 318). Hence, a grassroots sporting club for instance, is implicitly deemed a supportive member of the community in which it operates. However, much of the literature relating to sponsorship and CSR in sport is concerned with national professional sporting bodies (Sheth and Babiak, 2010), making any comparison with the sponsorship of grassroots properties difficult. For instance, Lacey at al. (2010) is among the rare studies investigating CSR perceptions accrued from sponsoring a sport property but it focuses on a large-scale national cycling event. Hence, little is known regarding the impact of the scope of the property (national versus a grassroots property) on its sponsor's CSR image.

Social impact theory has provided theoretical foundations for the role of organizational scope in CRM campaigns (Grau and Folse, 2007; Vanhamme et al., 2012). It suggests that the intensity of consumer responses to social stimuli depends on proximity to the physical source (Latane and Bourgeois, 2001). Therefore, consumers are more likely to donate to local causes than national ones (Hou et al., 2008). Moreover, Stebbins and Hartman (2013) show that consumers are more willing to give to local charities because they have distinct identities with high perceived benevolence. Applied to this context, sport properties located closer to consumers are perceived as more immediate, and therefore may exert stronger influence on consumer response (Grau and Folse, 2007). Hence, grassroots sponsorship should have a stronger effect on the sponsor's altruistic attributions compared to national sponsorship. Hence:

H2: A sports property's community proximity is positively associated with the attributions of altruistic motives to its sponsor; so that altruistic attributions are stronger for sponsors of grassroots than of national properties. 


\section{Corporate social responsibility image}

We also anticipate that motive inferences play an important intervening role within the sponsorship's chain of effect; in particular, we test this inference process as triggered by the property's community engagement. Research has highlighted the mediating role of altruistic motive attributions amongst consumers in a sponsorship context but little evidence exists regarding this inference mechanism in response to the sponsored entity's proactive CSR behavior (i.e., community engagement). For example, Pappu and Cornwell (2014) conceptualize the effects of socially oriented cause sponsorship based on corporate motives attribution but their study does not empirically focus on attributions. Rifon et al. (2004) show that inferences of commercial motives mediate the influence of a sponsorship's congruence (i.e., fit between the property and the sponsor) on attitudinal outcomes although CSR image was not tested. In addition, Dean (2002) finds that altruistic attributions mediate the relationship between the sponsorship of a charitable property such as the Special Olympics and perceived corporate community relations. Note, however, that this latter study is different from our investigation since the Special Olympics are inherently charitable whereas in our study the property engages in an external CSR activity. In sum, based on the important theoretical role of attributions and extant supporting evidence in sponsorship situations, we anticipate that the mediating role of altruistic motive attributions is the mechanism underlying the impact of the property's proactive community engagement on CSR image; thus:

H3: A sports property's community engagement has an indirect impact on its sponsor's CSR image through altruistic motive attributions.

As argued above, a property's active engagement in the community can sway stakeholders' beliefs about its worthiness, which helps in securing sponsorships. Such engagement is aligned with grassroots clubs, which are commonly perceived as integral to the social fabric 
of the community (Wicker et al., 2012). However, we anticipate that a property's proactive engagement will be less aligned with the perceptions of national properties, which are typically seen as less concerned with community issues (Sheth and Babiak, 2010).

Indeed, sponsoring professional sport organizations is unlikely to lead to an improved CSR image for the sponsor, unless the sport organization develops its own image as a caring and engaged corporate citizen (Quester et al., 2013). However, the same added benefits are unlikely to arise for sponsors of grassroots properties. As these sport organizations are already close to the community (Wicker et al., 2012), the opportunity for them to improve stakeholders' perceptions of their sponsors even further by proactively engaging in the community is limited. As a consequence, we anticipate that benefits for sponsors resulting from a property's community engagement efforts will be greater if the property is national rather than grassroots.

H4: The positive impact of a sporting property's proactive community engagement on its sponsor's CSR image is moderated by the property's community proximity; so that it is stronger for a national rather than a grassroots property.

\section{Method}

\section{Experimental Design}

A between-subjects experimental design was used to test the relevance of the property's community engagement and community proximity in determining altruistic attributions and, in turn, sponsor CSR image. The factorial design developed for this study thus comprises two factors: property community engagement (yes or no) and community proximity (grassroots or national). A third factor (perceived financial need of the property) was also included but, as will be explained later, did not affect the results. Stimulus material resembling an online newspaper article was composed for each condition of the $2 \times 2 \times 2$ factorial design. An 
example of a stimulus is shown in Appendix A. While many firms are likely to maintain a portfolio of sponsorships to achieve a multitude of objectives, this study focuses on individual sponsorships to allow for a clear delineation between the effects of sponsoring clubs with low/high community proximity and engagement. Following the stimulus material, a similar yet non-related newspaper article followed to curtail demand effect before respondents were exposed to survey questions. The articles were based on recent examples of a prominent newspaper in the Australian State of South Australia, with the stimulus and the respondent sample geographically defined for this area.

Two sporting clubs were chosen to reflect national (Adelaide Football Club) and grassroots (Blackwood Football Club) level properties. The former operates as one of only two South Australian professional national league clubs in the Australian Football Code, while the latter represents a locally based sporting club of amateur players, closely woven into the local community. Similarly, a South Australian based community initiative was utilized for the stimulus (Operation Flinders). It supports troubled or at risk teenagers through group wilderness adventure programs, the rough outdoor component of which is aligned with the sport chosen for this study.

To test the conceptual framework and thus simulate different sponsorship scenarios varying community proximity and property engagement in community initiatives, fictitious sponsorships using a fictitious sponsor were used. This approach not only controls for familiarity and brand personality of the sponsor due to a lack of prior exposure, it also enables experimental flexibility while ensuring ecological validity. Based on a pre-test of three fictitious companies undertaken with 60 university students, a landscape gardening business called Greenwall Solutions Pty Ltd was chosen as a suitable fictitious organization. Although the three candidate sponsors pretested exhibited the same product category relevance $(\mathrm{F}(2,57)=1.54, \mathrm{p}=.22)$, Greenwall was the only candidate sponsor to yield both a 
more positive brand attitude and a greater congruence with the football club than other candidates (Attitude: $F(2,57)=11.67, \mathrm{p}<.001$; Congruence: $\mathrm{F}(2,57)=2.99, \mathrm{p}=.058$, pairwise comparison: $\mathrm{p}=.05)$.

All measures employed in this survey were 7-point Likert-type scales adapted from the extant literature (respective sources and psychometric properties are outlined in Appendix B). While the measure for altruistic attributions reflects the perceived motives of the firm to engage in the sponsorship (Rifon et al., 2004), CSR image is measured as the perceived overall commitment of the firm to improve community well-being. Empirically these two constructs exhibit discriminant validity as their respective average variance extracted $\left(\mathrm{AVE}_{\text {Attribution }}=.46 ; \mathrm{AVE}_{\mathrm{CSR} \text { image }}=.81\right)$ exceed the square of their intercorrelation $(.41)$ (Fornell and Larcker, 1981). However, the AVE of altruistic attribution being below .50 warranted further investigation to more confidently assert its discriminant validity. Hence, we compared a model in which latent factors are freely correlated with another model in which they are perfectly correlated (Byrne, 2011). A Wald test revealed that constraining the correlation to one significantly decreases the model fit $\left(\chi^{2}=38.452, d f=1, p=.001\right)$. All measures exhibited satisfactory unidimensionality (variance explained by the first extracted factor is $67 \%$ and above) and reliability (> .76). In one exception, one of the items measuring altruistic attributions (i.e., "[Sponsor] sponsored the [club name] Football Club because sponsorship creates a positive image") was removed due to a weak item-to-total correlation $(<.37)$ with the three remaining items having item-to-total correlation of .54 or above.

In addition, the control variables familiarity with the sport club "I am not at all familiar with/I am very familiar with“" (one item adapted from Kent and Allen, 1994) and involvement with the sport club (three items adapted from Helmig, Huber and Leeflang, 1997) were included since they both have been shown to alter the processing of sponsorship stimuli (Cornwell, Weeks, and Roy, 2005; Olson, 2010). Demographic and manipulation check 
questions were also added. Perceptions relating to the community proximity and engagement in community initiatives were measured by means of single item semantic differential scales "According to your opinion about the scope of the club, is the [club] a local club - national club" and "According to your opinion, is the [club] involved in community programs? Not at all involved - very much involved".

\section{Sample}

Aiming for a general population sample of the State of South Australia, data was collected by means of an online panel. Samples accessed by means of online panels are commonly used for research in managerial and academic settings as they do not differ significantly from those contacted by traditional means, neither in terms of demographics nor attitudes (Deutskens et al., 2006). Participants were randomly assigned to one of four experimental groups. Data collection was continued until 400 complete, usable responses were achieved, with 100 responses per experimental group. The sample includes a slight majority of female respondents (54.5\%) and shows a mean age of 48 (ranging from 17 to 84 ). While a large proportion of respondents completed a high school diploma as their highest level of education (44\%), 30\% reported either an undergraduate or postgraduate degree. Despite minor variations, these characteristics remain consistent across all experimental groups.

\section{Results}

\section{Manipulation checks}

The manipulation of community proximity and engagement were successful. The main and interactions effects of the three manipulated factors entered in an ANOVA showed that the sponsored club was seen as more engaged in its community when it supported Operation Flinders than when it $\operatorname{did}$ not $(M=3.52$ versus $M=3.98 ; F(1,392)=70.15, p<.001$; see 
Table 1). In addition, a similar ANOVA conducted on community proximity showed that the Grassroots club was seen as more local than the national club $(\mathrm{M}=3.52$ versus $\mathrm{M}=3.98$; $\mathrm{F}(1,392)=77.7, \mathrm{p}<.001 ;$ see Table 1). Demographic variables such as gender, age, occupation and income were not related to the manipulated variables with the exception of education. Hence, control dummy variables for education were added in subsequent analyses (i.e., respondents whose highest levels of education were either primary school or professional school).

\section{Hypothesis testing}

First, we performed an analysis of covariance to test for the moderation prediction found in $\mathrm{H} 4$ that community engagement of the club is more beneficial for CSR image to sponsors when the sponsored club operates at the national rather than grassroots level. The two education level dummies from above were included as covariates as well as familiarity and involvement with the sport club. ANCOVA results show a significant interaction between community engagement and proximity $(\mathrm{F}(1,388)=2.64, \mathrm{p}=.05$, one-tailed; see Table 2$)$. Examining the means of sponsor CSR image helps illustrate the effect of community proximity: In the context of grassroots sponsorship, the club's community engagement did not significantly impact the sponsor's CSR image (MCommunity $=5.30$ vs. NoCommunity $=$ $5.06, \mathrm{~F}(1,192)=1.99, \mathrm{p}=.16)$. Whereas sponsoring a national football club that supports a charity program improved the sponsor's CSR image (MCommunity $=5.05$ vs. NoCommunity $=4.41, \mathrm{~F}(1,192)=12.41, \mathrm{p}=<.01)$. Furthermore, the CSR image ANCOVA in Table 2 shows that perceived financial need had neither a main nor moderating effects; hence, we performed the subsequent analysis of the indirect effect through altruistic attributions by collapsing results across the two perceived financial need conditions in order to make the model more parsimonious. We also note that a similar ANCOVA on altruistic attributions 
showed that perceived financial need did not influence this variable either through its main (F $(1,388)=1.10, \mathrm{p}=.29)$ or moderating effects $(\mathrm{Fs}<1.62$, ps $<.20)$.

$\mathrm{H} 1-\mathrm{H} 3$ were then tested with the non-parametric bootstrapping-based procedure developed by Hayes (2013) using the PROCESS software. By relying on empirically generated distributions, statistical significance of the indirect effects can be asserted via biascorrected bootstrapped confidence intervals. This procedure does not rest on the questionable assumptions of the normal theory approach (e.g., the Sobel test, the causal step strategy) regarding the distribution of the indirect effects in the population (Preacher and Hayes, 2008). In addition, PROCESS tests for moderation effects through conditional analysis according to which the indirect and direct effects are contingent upon values taken by the moderator(s).

In order to test for H1-H3, the model included the following: The property's community engagement as the independent variable, sponsor altruistic motive attributions as the mediator and sponsor's CSR image as the dependent variable. Furthermore, the property's community proximity is both included as an antecedent to attributions and as a moderator of the impact of community engagement on sponsor CSR image (the education level dummies, as well as familiarity and involvement with the property, are also included as covariates).

As shown in Table 3, sponsoring a sport club engaged in the community rather than a club not engaged influences positively perceived altruistic motives attributions (parameter $=$ .36 , CI95\% $=.09$ to .63 ), which supports H1. Similarly, sponsoring a grassroots rather than a national sporting club leads to stronger altruistic attributions for the sponsor (parameter $=.67$, $\mathrm{CI} 95 \%=.35$ to .99$)$, supporting $\mathrm{H} 2$.

[Insert Table 3 about here]

Regarding the mediating impact of altruistic attributions, we first note that the support found above for $\mathrm{H} 1$ regarding the positive influence of community engagement on altruistic attributions coupled with the positive and significant impact of the latter on CSR image 
(parameter $=.75$, CI95\% $=.65$ to $.85-$ see Table 3$)$ are consistent with this hypothesis. In addition, we performed a conditional analysis in order to conduct a more formal test of the indirect effect of community engagement through altruistic attributions. Results indicate that this effect is positive and significant for the two possible conditions (national club: parameter $=.27, \mathrm{CI} 95 \%=.07$ to .48 ; grassroots club: parameter $=.21, \mathrm{CI} 95 \%=.01$ to .41$)$. Since the indirect effect of community engagement through altruistic attributions is found in all conditions investigated, the mediating impact of altruistic attributions formulated in $\mathrm{H} 3$ is supported.

We also note that, in further support of $\mathrm{H} 4$, the impact of proactive community engagement is stronger for the national versus grassroots scope club since it is positive and significant only in the national scope condition. According to the conditional analysis, the direct effect of club community engagement on sponsor CSR image is not significant for the grassroots sporting club (parameter $=.02, \mathrm{CI} 95 \%=-.25$ to .29 ). On the other hand, for the national club, the direct effect of community engagement on sponsor CSR image is significant $($ parameter $=.34, \mathrm{CI} 95 \%=.06$ to .62$)$.

\section{Discussion}

The main objective of this study was to investigate the attributes of a sport property that are most conducive to CSR image benefits experienced by its sponsor. More specifically, the central thrust of our investigation was to provide insights into the extent to which a sports property's proactive engagement in the community, rather than that of the sponsoring firm itself, enhances CSR image for the sponsor, particularly when the property is of a national rather than a grassroots scope. Furthermore, building on attribution theory, we also showed the role of consumers' inference of the sponsor's goodwill in driving these effects.

\section{Theoretical Implications}


A significant contribution of this study lies in showing how certain features of a sport's property can drive CSR image perceptions of its sponsor. The extant literature has evidenced a wide array of benefits accrued by firms with a strong CSR image (e.g., Close et al., 2006; Luo and Bhattacharya, 2009); however, this focus on CSR image consequences has outshone research efforts on its antecedents. As a result, this study's findings that sports property can imbue sponsors with positive CSR perceptions if they are either close to their community or are proactively engaged in it, although the sponsor is not directly partaking in CSR initiative, fills an important gap in the understanding of CSR image drivers. These results complement the burgeoning literature on the sponsorship benefits of properties with a more altruistic reputation as demonstrated by Mazodier and Rezaee (2013), who found that announcing the sponsorship of a philanthropic rather than commercial property was better received by the firm`s shareholders. Our results show that the advantages of such properties are manifested trough consumers' perceptions of the firm's CSR image as well.

More specifically, the conditional direct effect analysis demonstrated that sponsoring a property that is engaged in the community influenced positively CSR image if the property is of national rather than grassroots scope. Indeed, the most favorable CSR image emerged for the organization sponsoring a grassroots club with active community engagement, followed by similar results for the grassroots club without engagement and the national club with engagement, with the lowest CSR image score recorded for a national club not engaging in community initiatives. This effect was expected due to the assuaging role of altruistic motive attributions: Supporting a national property with a mass-appeal but strong undertones of commercialism is likely to suggest self-serving economic rather than altruistic motives for the sponsor (Meenaghan, 2001). Yet, if the property develops its image as a caring and engaged corporate citizen by supporting community initiatives, the same sponsorship may be seen as supporting a worthwhile organization, which will counterbalance the negative impact of 
national scope; as shown by the stronger altruistic attributions evidenced in our results. The grassroots property, on the other hand, is deemed a worthy recipient of sponsorship investment irrespective of its community engagement, given its close proximity to the community in which it operates (Wicker et al., 2012). Our results thus speak directly to this phenomenon by evidencing a positive effect of grassroots versus national sport property on altruistic attributions.

As highlighted previously, while the mass appeal, high visibility and media presence of sport provide unique opportunities for sponsors, these characteristics imply that sports properties are not commonly thought of as effective vehicles for swaying consumers' attributions toward altruism (and ultimately their CSR perceptions) (Meenaghan, 2001; Pappu and Cornwell, 2014). However, our results demonstrate that even within the sport context, altruism can also play an important role for sponsors, as a function of the property's scope (i.e., sponsoring a national rather than a grassroots sports property). This is a key consideration since goodwill perceptions are among the defining features of sponsorship as a communication medium (in comparison with advertising or sales promotion) on which much of its effectiveness rests (Carrillat and d'Astous, 2012).

Furthermore, our study provides the evidence for a strong mediating effect of altruistic motives in the relationships between the community engagement of the sports property and the sponsor's CSR image. When interpreting this finding within the broader set of existing results on altruistic attributions, the contribution of the present study is even more evident. Walker et al (2010) found a mediating role of attributions but none of the property attributes were investigated. Furthermore, Rifon et al. (2004) examined one such factor and found that congruency (between the sponsor and the sport property) was more conducive to altruistic attributions than incongruity; while Dean (2002) showed that sponsoring a charitably inclined organization yielded some beneficial reputation effects. Importantly, none of these studies 
demonstrated how a behavior performed by the sponsored organization (i.e., deciding to be proactively engaged in the community), as opposed to being inherently close to the community through a grassroots scope, could influence consumers' response positively due to altruistic attributions. As a corollary of the above, ours is the first study that demonstrates the indirect attribution of altruism motives to the sponsor of the property exhibiting altruism without the firm having to demonstrate benevolence of its own.

\section{Managerial Implications}

Important managerial implications follow from this study for managers of both sides of a sport sponsorship dyad. Most prominently, marketing and sponsorship managers may confidently index sport sponsorship as an initiative facilitating the development of a CSR image, benefiting not only from the altruism attributed to such behavior and resultant CSR image, but also from the high visibility, prominence and emotions relating to sport. Indeed, the sponsorship of properties that actively engage in the community offers a win-win-win situation, in which properties benefit from the corporate sponsorship, sponsors gain through an enriched CSR image, and community organizations secure valuable support from the property.

Our study unveiled an important potential source of competitive advantage regarding CSR perceptions. Many sponsors seek involvement with national sports propertys due to their ability to communicate with mass audiences (Gijsenberg, 2014). For sponsors incorporating CSR image building as part of their sponsorship objectives, the property's active engagement in community initiatives should form part of the decision criteria determining choice of property. Alternatively, firms can encourage properties to develop or increase their engagement with charities as part of their sponsorship negotiations. Our results show that the community initiatives of a national sports property allow sponsors to achieve an enhanced 
CSR image whereas sponsors of a grassroots property do not garner added benefits from such engagement. Hence, by sponsoring a national sports property prominently engaged in the community, the high visibility and name recognition that such property offers can be coupled with an improved CSR image.

Sponsorship managers can control a sponsorship portfolio (Chien et al., 2011); often composed of a variety of national and grassroots sports properties. The positive influence of community initiatives for national property sponsorship indicates that a balanced portfolio is a sound strategy. Grassroots properties offer potential due to their inherent community association, which many properties accentuate by proactive engagement in the community in which they operate. However, focusing solely on grassroots properties when aiming at CSR improvement is not a necessity; opening possibilities of more diverse portfolios.

Mirroring implications for marketing and sponsorship managers of current or potential sponsoring organizations, managers of sports propertys may utilize our findings to attract new sponsors seeking to improve their CSR image through sport, and maintain or enhance contribution from current ones. Importantly, while confirming the potential of grassroots propertys in building goodwill towards the sponsor, those properties operating on a national level may wish to seek or develop community initiatives to support in order to offer their sponsors the goodwill inference opportunities achievable in a sporting context.

\section{Limitations and future research opportunities}

Limitations of this research should be considered in the development of a future research agenda in this field. Our particular focus on one sport and one geographical region in Australia poses a limitation that should be overcome by replicating this study in different settings. Extensions of the research may broaden the sample to include consumers on a national rather than State level and build on our research to test for portfolios of properties 
rather than a single sponsorship. While the use of only one sponsor, characterized by a firm with a positive brand attitude in a high-fit sponsorship setting, reflects another limitation of this study, the characteristics of this sponsor were chosen based on the extensive literature attesting the importance of fit to achieve favorable sponsorship outcomes (Pappu and Cornwell, 2014).

Furthermore, while the experiment provided a valuable means to test the hypotheses developed in this study, future research should confirm our results in the field, measuring directly for community proximity rather than relying on the proxy of property scope in an experimental setting. To further advance our understanding of the role sport sponsorship can play in developing and/or changing stakeholder perceptions of the sponsor's CSR image, a longitudinal rather than cross-sectional approach would be of value. Such studies may also wish to examine the potential effect that some characteristics of the sport organization's community engagement (such as the frequency, longevity and cause supported) may have on sponsor outcomes.

Similarly, research should undertake a comprehensive investigation of CSR initiatives, examining the relative impact sport sponsorship may have on CSR image compared to the portfolio of multiple CSR initiatives an organization can draw upon, considering a multitude of outcome measures, such as purchase intent and word of mouth. Such investigation will also allow for a comparison between the sponsorship of sport properties, which may or may not engage with charities, with the direct sponsorship of charities.

Finally, the activation and communication of the firm's support of properties is an essential element of a sponsorship strategy, which has been shown to entail synergies in terms of brand awareness and purchase intents (Cornwell et al., 2005). Investigating whether similar synergies can be achieved in terms of CSR image perception with properties of different engagement levels in their community is therefore warranted in further research 
endeavor. Note however, that while research suggests that considerable benefits could be gained by sponsors communicating CSR initiatives such as when the sponsored property has closely tied to the community, communication that is perceived as not credible is likely to have negative consequences for sponsors (Rifon et al., 2004). Hence, further research should investigate the effects of sport sponsorship on brand image, when consumers do trust the sponsor and perceive its motives as self-centric.

As CSR permeates organizations in all industries and of all sizes, managers are increasingly asked to identify the ability of their initiatives to contribute to the organization's socially responsible image across its stakeholder groups. While sport sponsorship has not commonly been deemed as promising in developing goodwill perceptions for sponsors, this study highlights the potential of sport sponsorship to increase a firm's CSR image. More specifically, it shows that a property's proactive engagement in the community improves its sponsor's CSR image especially when it operates on a national rather than grassroots level. Organizations supporting grassroots properties, on the other hand, benefit from their sponsorship because they support a sports property in close proximity to the community, independent of whether the property proactively engages in the community or not. 


\section{References}

Babiak, K., \& Wolfe, R. (2009), “Determinants of corporate social responsibility in professional sport: Internal and external factors", Journal of Sport Management, Vol. 23 No. 6, pp. 717-742.

Berens, G., van Riel, C. B. M., \& van Bruggen, G. H. (2005), "Corporate associations and consumer product responses: The moderating role of corporate brand dominance", Journal of Marketing, Vol. 69 No. 3, pp. 35-48.

Bigné, E., Currás-Pérez, R., and Aldás-Manzano, J. (2012), “Dual nature of cause-brand fit: Influence on corporate social responsibility consumer perception”, European Journal of Marketing, Vol. 46 Nos. 3/4, pp. 575-594.

Bradish, C., \& Cronin, J. J. (2009), “Corporate social responsibility in sport”, Journal of Sport Management, Vol. 23 No. 6, pp. 691-697.

Brooks, C. (2013, May 22), "Social responsibility no longer optional for businesses", available at: http://www.businessnewsdaily.com/4528-social-responsibility-notoptional.html (accessed 25 January 2015).

Brown, T. J., \& Dacin, P. A. (1997), “The company and the product: Corporate associations and consumer product responses", Journal of Marketing, Vol. 61 No. 1, pp. 68-84.

Byrne, B. M. (2011). Structural Equation Modeling with Mplus: Basic Concepts, Applications, and Programming, Multivariate Applications Series, Routledge.

Carrillat, F.A. \& d'Astous, A. (2012), “The sponsorship-advertising interface: Is less better for sponsors?”, European Journal of Marketing, Vol. 46 Nos. 3/4, pp. 562-574.

Chien, P. M., Cornwell, T. B., \& Pappu, R. (2011), "Sponsorship portfolio as a brand-image creation strategy", Journal of Business Research, Vol. 64 No. 2, pp. 142-149. 
Close, A.G., Finney, R. Z., Lacey, R. Z. \& Sneath, J. Z. (2006), "Engaging the consumer through event marketing: linking attendees with the sponsor, community, and brand", Journal of Advertising Research, Vol. 46 No. 4, pp. 420-433.

Cornwell, T. B., Weeks, C. S., \& Roy, D. P. (2005), “Sponsorship-linked marketing: Opening the black box", Journal of advertising, Vol. 34 N0. 2, pp. 21-42.

Dean, D.H. (2002), “Associating the corporation with a charitable event through sponsorship: Measuring the effects on corporate community relations", Journal of Advertising, Vol. 31, pp. $77-87$.

Deutskens, E. C., de Jong, A., de Ruyter, K., \& Wetzels, M. (2006), “Comparing the generalizability of online and mail surveys in cross-national service quality research”, Marketing Letters, Vol. 17 No. 2, pp. 119-136.

Du, S., Bhattacharya, C. B., \& Sen, S. (2010), "Maximising business returns to corporate social responsibility (CSR): The role of CSR communication", International Journal of Management Reviews, Vol. 12 No. 1, pp. 8-19.

Fornell, C. \& Larcker, D. F. (1981), "Structural Equation Models with Unobservable Variables and Measurement Error: Algebra and Statistics," Journal of Marketing Research, Vol. 18 No. 3, pp. 382-388.

Gijsenberg, M. J. (2014), “Going for gold: Investigating the (non)sense of increased advertising around major sport events", International Journal of Research in Marketing, Vol. 31 No. 1, pp. 2-15.

Grau, S. L., \& Folse, J. A. G. (2007), “Cause-related marketing (CRM): The influence of donation proximity and message-framing cues on the less-involved consumer", Journal of Advertising, Vol. 36 No. 4, pp. 19-33.

Hayes, A.F. (2013), Introduction to Mediation, Moderation, and Conditional Process Analysis: A Regression-Based Approach, Guilford Press, New York. 
Helmig, B., Huber, J. A., \& Leeflang, P. (2007), "Explaining behavioural intentions toward co-branded products“, Journal of Marketing Management, Vol. 23 No. 3-4, pp. 285-304.

Hildebrand, D., Sen, S., and Bhattacharya, C. B. (2011), “Corporate social responsibility: a corporate marketing perspective", European Journal of Marketing, Vol. 45 No. 9/10, pp. $1353-1364$.

Hou, J., Du, L., \& Li, J. (2008), “Cause’s attributes influencing consumer's purchasing intention: Empirical evidence from China", Asia Pacific Journal of Marketing and Logistics, Vol. 20 No. 4, pp. 363-380.

IEG (2014), "What sponsors want from partners - The most important benefits, services and objectives", available at: http://www.sponsorship.com/IEG/files/7f/7f60c23c-43d6-4006bc7d-2c32c5e83c1d.pdf (accessed 14 May 2015).

IEG (2015), "Sponsorship spending report - Where the dollars are going and trends for 2015", available at: http://www.sponsorship.com/IEG/files/4e/4e525456-b2b1-4049-bd5103d9c35ac507.pdf (accessed 14 May 2015).

Jahadi, K., \& Acikdilli, G. (2009), "Marketing communications and corporate social responsibility (CSR): Marriage of convenience or shotgun wedding?" Journal of Business Ethics, Vol. 88 No. 1, pp. 103-113.

Jarvie, G. (2013), Sport, culture and society: An introduction, $2^{\text {nd }}$ edition, Routledge, London.

Kent, R. J., \& Allen, C. T. (1994), “Competitive interference effects in consumer memory for advertising: the role of brand familiarity", Journal of Marketing, Vol. 58 No. 3, pp. 97105.

Kotler, P., \& Lee, N. (2004), Corporate social responsibility: Doing the most good for your company and your cause, John Wiley and Sons, New Jersey. 
Lacey, R., Close, A. G., \& Finney, R. Z. (2010), “The pivotal roles of product knowledge and corporate social responsibility in event sponsorship effectiveness", Journal of Business Research, Vol. 63 No. 11, pp. 1222-1228.

Lichtenstein, D. R., Drumwright, M. E., \& Braig, B. M. (2004), "The effect of corporate social responsibility on customer donations to corporate-supported nonprofits", Journal of Marketing, Vol. 68 No.4, pp. 16-32.

Luo, X., \& Bhattacharya C. B. (2006), "Corporate social responsibility, customer satisfaction, and market value", Journal of Marketing, Vol. 70 No. 4, pp. 1-18.

Luo, X., \& Bhattacharya C. B. (2009), “The debate over doing good: corporate social performance, strategic marketing levers, and firm-idiosyncratic risk", Journal of Marketing, Vol. 73 No. 6, pp. 198-213.

Latane, B., \& Bourgeois, M. J. (2001), "Dynamic social impact and the consolidation, clustering, correlating, and continuing diversity of culture”, in Hogg, M. A. \& Tindale, R. S. (Eds.), Blackwell Handbook of Social Psychology: Group Processes, Oxford, Blackwell, pp. 235-238.

Mazodier, M., Rezaee, A. (2013), “Are sponsorship announcements good news for the shareholders? Evidence from international stock exchanges", Journal of the Academy of Marketing Science, Vol. 41 No. 5, pp. 586-600.

Meenaghan, T. (2001), “Understanding sponsorship effects”, Psychology and Marketing, Vol. 18 No. 2, pp. 95-122.

Menon, S., \& Kahn, B. (2003), “Corporate sponsorships of philanthropic activities: When do they impact perception of sponsor brand?", Journal of Consumer Psychology, Vol. 13 No. 3, pp. 316-327.

Olson, E.L. (2010), "Does sponsorship work in the same way in different sponsorship contexts?”, European Journal of Marketing, Vol. 44 Nos. 1/2, pp. 180-199. 
Pappu, R., \& Cornwell, T. B. (2014), “Corporate sponsorship as an image platform:

Understanding the roles of relationship fit and sponsor-sponsee similarity", Journal of the Academy of Marketing Science, Vol. 42 No. 5, 490-510.

Peloza, J., \& Shang, J. (2011), "How can corporate social responsibility activities create value for stakeholders? A systematic review", Journal of the Academy of Marketing Science, Vol. 39 No. 1, pp. 117-135.

Pérez, A., Salmones, M.M.G. and Bosque, I.R. (2013), "The effect of corporate associations on consumer behavior”, European Journal of Marketing, Vol. 47, Nos. 1/2, pp. 218-238.

Plewa, C., \& Quester, P. (2011), “Sponsorship and CSR: Is there a link? A conceptual framework", International Journal of Sports Marketing \& Sponsorship, Vol. 12 No. 4, pp. 301-317.

Preacher, K. J., \& Hayes, A. F. (2008), “Asymptotic and resampling strategies for assessing and comparing indirect effects in multiple mediator models", Behavior Research Methods, Vol. 40 No. 3, pp. 879-891.

Quester, P., Plewa, C., Palmer, K., \& Mazodier, M. (2013), “Determinants of communitybased sponsorship impact on self-congruity", Psychology \& Marketing, Vol. 30 No. 11, pp. 996-1007.

Rifon, N. J., Choi, S. M., Trimble, C. S., \& Li, H. (2004), “Congruence effects in sponsorship: The mediating role of sponsor credibility and consumer attributions of sponsor motive", Journal of Advertising, Vol. 33 No. 1, pp. 30-42.

Sheth, H., \& Babiak, K. M. (2010), "Beyond the game: Perceptions and practices of corporate social responsibility in the professional sport industry", Journal of Business Ethics, Vol. 91 No. 3, pp. 433-45.

Simmons, C. J., \& Becker-Olsen, K. L. (2006), “Achieving marketing objectives through social sponsorships", Journal of Marketing, Vol. 70 No. 4, pp. 154-169. 
Skard, S., \& Thorbjornsen, H. (2014), "Is publicity always better than advertising? The role of brand reputation in communication corporate social responsibility", Journal of Business Ethics, Vol. 124 No. 1, pp. 149-160.

Speed, R., \& Thompson, P. (2000), “Determinants of sports sponsorship response”, Journal of the Academy of Marketing Science, Vol. 28 No. 2, pp. 226-238.

Sportbusiness (2009), “Companies see value sport social change”, available at: http://www.sportbusiness.com/britsport/169464/companies-see-value-sport-social-change (accessed 28 September 2011).

Stebbins, E., \& Hartman, R. L. (2013), “Charity brand personality: can smaller charitable organizations leverage their brand's personality to influence giving", International Journal of Nonprofit and Voluntary Sector Marketing, Vol. 18, pp. 203-215.

Vaaland, T.I., Heide, M., and Grønhaug, K. (2008), “Corporate social responsibility: Investigating theory and research in the marketing context", European Journal of Marketing, Vol. 42 Nos. 9/10, pp. 927-953.

Vanhamme, J., Lindgreen, A., Reast, J., \& Van Popering, N. (2012), “To do well by doing good: Improving corporate image though cause-related marketing", Journal of Business Ethics, Vol. 109 No. 3, pp. 259-274.

Varadarajan, P. R., \& Menon, A. (1988), “A coalignment of marketing strategy and corporate philanthropy", Journal of Marketing, Vol. 52 No. 3, pp. 58-74.

Walker, M., Heere, B., Parent, M. M., \& Drane, D. (2010), “Social responsibility and the Olympic Games: The mediating role of consumer attributions”, Journal of Business Ethics, Vol. 95 No. 4, pp. 659-680.

Walker, M., \& Kent, A. (2009), "Do fans care? Assessing the influence of corporate social responsibility on consumer attitudes in the sport industry", Journal of Sport Management, Vol. 23 No. 6, pp. 743-769. 
Wicker, P., Breuer, C., \& Hennigs, B. (2012), "Understanding the interactions among revenue categories using elasticity measures - Evidence from a longitudinal sample of non-profit sport clubs in Germany", Sport Management Review, Vol. 15 No. 3, pp. 318329. 